\title{
Article 22. Capacity
}

1. The Parties shall cooperate in the capacity-building, capacity development and strengthening of human resources and institutional capacities to effectively implement this Protocol in developing country Parties, in particular the least developed countries and small island developing States among them, and Parties with economies in transition, including through existing global, regional, subregional and national institutions and organisations. In this context, Parties should facilitate the involvement of indigenous and local communities and relevant stakeholders, including non-governmental organisations and the private sector.

2. The need of developing country Parties, in particular the least developed countries and small island developing States among them, and Parties with economies in transition for financial resources in accordance with the relevant provisions of the Convention shall be taken fully into account for capacity-building and development to implement this Protocol.

3. As a basis for appropriate measures in relation to the implementation of this Protocol, developing country Parties, in particular the least developed countries and small island developing States among them, and Parties with economies in transition should identify their national capacity needs and priorities through national capacity selfassessments. In doing so, such Parties should support the capacity needs and priorities of indigenous and local communities and relevant stakeholders, as identified by them, emphasising the capacity needs and priorities of women.

4. In support of the implementation of this Protocol, capacity-building and development may address, inter alia, the following key areas:

(a) Capacity to implement, and to comply with the obligations of, this Protocol;

(b) Capacity to negotiate mutually agreed terms;

(c) Capacity to develop, implement and enforce domestic legislative, administrative or policy measures on access and benefitsharing; and

(d) Capacity of countries to develop their endogenous research capabilities to add value to their own genetic resources. 
5. Measures in accordance with paragraphs 1 to 4 above may include, inter alia:

(a) Legal and institutional development;

(b) Promotion of equity and fairness in negotiations, such as training to negotiate mutually agreed terms;

(c) The monitoring and enforcement of compliance;

(d) Employment of best available communication tools and Internet-based systems for access and benefit-sharing activities;

(e) Development and use of valuation methods;

(f) Bioprospecting, associated research and taxonomic studies;

(g) Technology transfer, and infrastructure and technical capacity to make such technology transfer sustainable;

(h) Enhancement of the contribution of access and benefit-sharing activities to the conservation of biological diversity and the sustainable use of its components;

(i) Special measures to increase the capacity of relevant stakeholders in relation to access and benefit-sharing; and

(j) Special measures to increase the capacity of indigenous and local communities with emphasis on enhancing the capacity of women within those communities in relation to access to genetic resources and/or traditional knowledge associated with genetic resources.

6. Information on capacity-building and development initiatives at national, regional and international levels, undertaken in accordance with paragraphs 1 to 5 above, should be provided to the Access and Benefit-sharing clearing-house with a view to promoting synergy and coordination on capacity-building and development for access and benefit-sharing.

\section{$1 \quad$ Overview}

The length of this provision signals at the outset the paramount importance of capacity building for the successful implementation of the Protocol and for sensuring compliance with it. The Protocol addresses capacity building in detail, linking it to implementation and compliance, negotiation of MAT, development and enforcement of domestic ABS frameworks, and development of endogenous research capabilities. ${ }^{1}$ The following sections will analyze

1 Nagoya Protocol Article 22(4). 
the obligation to cooperate in this context, the emphasis on country-driven capacity building, and provisions specifically targeting indigenous and local communities. The final section will offer an assessment of possible challenges in development cooperation for ABS capacity building.

\section{The Obligation to Cooperate}

Article 22 creates an unconditional obligation for all Parties to cooperate in building capacity ${ }^{2}$ for the implementation of the Protocol. The obligation is underpinned by concerns about optimal utilization of resources and avoidance of duplicative activities. As per standard СвD terminology, the provision singles out two groups of countries that will benefit from capacity-building support: developing-country Parties, in particular the least developed countries and small island developing States among them, and Parties with economies in transition. ${ }^{3}$

Article 22, therefore, embodies an obligation of solidarity - that is, an intensified form of international cooperation, whereby individual States are to take into consideration in their own policy the interests of other States and the common interests of the global community, and be ready to accept to bear certain costs and burdens of cooperation. ${ }^{4}$ This is based on the understanding that costs and burdens have been distributed fairly 'in accordance with basic principles of equity and social justice' to address global challenges. ${ }^{5}$ Obligations of solidarity are to be fulfilled without expectations of reciprocity, and can be

2 On the different meanings of the expressions 'capacity-building,' 'capacity development' and 'strengthening of human resources and institutional capacities,' see Greiber et al., Explanatory Guide, op. cit., 207-208, relying on: "UN Public Administration Glossary," Un, accessed 30 November 2013, <www.unpan.org>.

3 The first two paragraphs of Nagoya Protocol Article 22 are modelled after Biosafety Protocol Article 22.

4 Wolfrum, "Cooperation," op. cit., paragraph 3.

5 UN General Assembly, "Promotion of a Democratic and Equitable International Order" (8 February 2002) Un Doc A/REs/56/151, paragraph 3(f), and "Promotion of a Democratic and Equitable International Order" (25 February 2003) un Doc A/REs/57/213, paragraph $4(\mathrm{f})$, which (both) read: 'Solidarity, as a fundamental value, by virtue of which global challenges must be managed in a way that distributes costs and burdens fairly, in accordance with basic principles of equity and social justice, and ensures that those who suffer or benefit the least receive help from those who benefit the most.' See also un Millennium Declaration, paragraph 6; and Campanelli, "Solidarity," op. cit., paragraph 17. 
considered inherent to specific areas of international law such as sustainable development and human rights. ${ }^{6}$

Article 22(1) can be interpreted as requiring Parties to enter into negotiations with a view to engaging in the coordinated or joint determination and allocation of capacity-building support. However, if agreement cannot be reached, the obligation does not impede Parties from making unilateral determinations, but in doing so they are expected to take in consideration other Parties' initiatives and concerns. ${ }^{7}$ While Article 22 does not provide specific indications as to how such cooperation should be carried out, it suggests recourse to existing global, regional, subregional and national institutions and organizations. These institutions may include the Global Environment Facility (GEF), ${ }^{8}$ the ITPGRFA and the multi-donor ABs Capacity Development Initiative, ${ }^{9}$ as well as the СвD itself through its Action Plan on Capacity-building for Access to Genetic Resources and Benefit-sharing. ${ }^{10}$

In addition, Article 22 does not prevent cooperation among Parties to be carried out on an ad hoc basis, including through bilateral agreements (specifically related to ABS or having a broader scope). ${ }^{11}$ The usefulness and costeffectiveness of subregional and regional approaches to capacity-building and development, in particular where countries have similar biological resources and common capacity-building and development needs, have also been underscored in intergovernmental discussions preparing for the entry into force of the Protocol. ${ }^{12}$ Based on these intergovernmental discussions, it can also be expected that the Protocol's governing body will facilitate coordination on capacity-building, through reporting, creating a specific coordination

6 Ibid., paragraphs 5-6 and 9-10, and 16-20 specifically on sustainable development.

7 See discussion on the general duty of cooperation in this commentary on Article 11, section 2.

8 Note that the GEF is also the financial mechanism for the implementation of the CBD and the Nagoya Protocol: see this commentary on Article 25, section 2.

9 ICNP Recommendation 1/2, "Measures to assist in capacity-building, capacity development and strengthening of human resources and institutional capacities in developing countries and Parties with economies in transition" in ICNP, "Report of the first meeting," UNEP/CBD/ICNP/1/8, Annex, 2nd preambular recital.

СвD Decision 7/19, "Access and benefit-sharing as related to genetic resources (Article 15)" Annex (13 April 2004) un Doc Unep/cBD/cop/7/21. See also "Database of ABs Capacity-Building Activities,” свD, accessed 30 November 2013, <www.cbd.int/abs/ projects.shtml>; and Greiber et al., Explanatory Guide, op. cit., 206-207.

11 See discussion of bilateral agreements in this commentary on Article 4, section 3. ICNP Recommendation 1/2, 5th preambular recital. 
mechanism, and monitoring and reviewing of activities undertaken. ${ }^{13}$ This will build upon information (that 'should' be provided) on capacity-building activities to the ABS Clearinghouse. ${ }^{14}$ By storing and sharing information on capacity-building materials, the ABs Clearinghouse is itself expected to contribute to capacity building. ${ }^{15}$

In cooperating on capacity building, Parties are to operate in the framework of relevant provisions of the СвD on technical cooperation and financial solidarity. Article 22(1) implicitly refers back to the $\mathrm{CBD}$ requirement for Parties to undertake technical and scientific cooperation, especially with respect to the development and strengthening of national capabilities in human resources development and institution building. ${ }^{16}$ According to Article 22(2), the financial needs of developing countries shall be taken into full account for capacity building to implement the Protocol. Explicit reference, in that context, to 'accordance with relevant provisions of the Convention' may thus be interpreted as a reference to $\mathrm{CBD}$ requirement for developed countries to provide 'new and additional financial resources' to developing countries to enable them to meet the costs of implementing their obligations under the CBD. ${ }^{17}$ It may also refer to the $\mathrm{CBD}$ text on taking into account that the implementation by developing countries of their international obligations will depend on the degree to which developed country Parties provide financial resources to the former. ${ }^{18}$

13 ICNP Recommendation $1 / 2$, paragraph 1 and Annex, where reference is made to a coordination mechanism and its possible elements, including the reporting of capacitybuilding and development initiatives to the ABs Clearinghouse; and monitoring and review, including developing a set of indicators to facilitate the monitoring and review of the implementation of the strategic framework and to assess the impact of access and benefit-sharing capacity-building and development initiatives.

14 Nagoya Protocol Article 22(6). See this commentary on Article 14, section 4.

15 See this commentary on Article 14, section 3.

16 свD Article 18. See Glowka, Burhenne-Guilmin and Synge, Guide to the Convention on Biological Diversity, op. cit., 94-95; and similarly to the corresponding text in the Biosafety Protocol, see Mackenzie et al., Explanatory Guide to the Cartagena Protocol, op. cit., 143. СвD Article 20(2). See Glowka, Burhenne-Guilmin and Synge, Guide to the Convention on Biological Diversity, op. cit., 102-104.

18 Свр Article 20(4). See Glowka, Burhenne-Guilmin and Synge, Guide to the Convention on Biological Diversity, op. cit., 105. Similarly to the corresponding text in the Biosafety Protocol, see Mackenzie et al., Explanatory Guide to the Cartagena Protocol, op. cit., 144145. On the interpretation of свр Article 20(4), see Melinda Chandler, "The Biodiversity Convention: Selected Issues of Interest to the International Lawyer," Colorado Journal of International Environmental Law and Policy 4 (1993): 141, 173-174, who sees it as a mere statement of fact; while Birnie, Boyle and Redgwell, International Law and the 


\section{Country-Driven Capacity-Building}

Because of the Protocol's built-in flexibility, capacity-building activities will vary greatly from one country to another. So intergovernmental discussions in preparation for the Protocol's entry into force have tried to balance a bottomup approach to allow countries, as well as indigenous and local communities, to determine their own needs with an overarching global strategy to ensure optimal use of resources. ${ }^{19}$

Article 22 thus seems to recognize that no single model of capacity building for ABS will fit the situation of all countries, but that capacity-building initiatives should be tailored to fit the specific national context of the country whose capacity is being developed. ${ }^{20}$ Notably, Article $22(3)$ points to the desirability of demand-driven capacity-building cooperation. It recommends that beneficiary countries identify their national capacity needs and priorities through national capacity self-assessments.

Article 22(4) then proceeds with an indicative list of key areas for capacity building (development, implementation and enforcement of domestic ABS measures; compliance with the Protocol; negotiations of MAT; and development of endogenous research capabilities to add value to one country's own genetic resources). ${ }^{21}$ Furthermore, Article 22(5) includes an indicative list of activities, ${ }^{22}$ such as the enhancement of the contribution of ABs activities to the conservation of biodiversity and the sustainable use of its components, which resonates with other provisions in the Protocol aimed at ensuring a holistic approach to the fulfillment of the three objectives of the CBD in the context of the Protocol. ${ }^{23}$ Reference is also made to technology transfer, which is specifically addressed elsewhere in the Protocol. ${ }^{24}$

Several of the key capacity-building areas and activities have to do with national law-making and implementation of the Protocol through legal means,

Environment, op. cit., 633-634, emphasise that the effect of this provision is to subject developing countries' compliance with international biodiversity policies to the extent that they receive funding under the Convention.

19 ENB 9/551, "Summary of the First Meeting of the Intergovernmental Committee for the Nagoya Protocol," 12.

20 See similar comments in relation to the Biosafety Protocol in Mackenzie et al., Explanatory Guide to the Cartagena Protocol, op. cit., 143.

21 Nagoya Protocol Article 22(4).

22 Nagoya Protocol Article 22(5).

23 See this commentary on Article 1, section 4; Article 5, section 6; Article 8, section 2; Article 9, section 2; Article 10, section 4; Article 12, section 5; and Article 21, section 3.

24 See this commentary on Article 23. 
including the need to ensure fairness in MAT, as well as to build institutional, scientific and other capacities to be able to fully and effectively apply and ensure compliance with domestic ABS frameworks. ${ }^{25}$

The Capacity of Indigenous and Local Communities and Other A BS Stakeholders

Article 22 makes several references (albeit of a recommendatory - rather than mandatory - character) to the capacity needs and priorities of indigenous and local communities, in recognition of their role in implementing the Protocol and their specific needs and rights. Thus, the provision recommends that Parties facilitate the involvement of these communities in cooperation on capacity-building ${ }^{26}$ and support the self-identification of capacity needs and priorities of these communities in the context of national capacity selfassessments. It highlights the need to pay specific attention to the capacity needs and priorities of women. ${ }^{27}$ Among specific measures for capacity building, reference is made to measures to increase the capacity of communities, particularly women, in relation to access ${ }^{28}$ to genetic resources and/or traditional knowledge. ${ }^{29}$ In this regard Article 22 is informed by and must be interpreted in conjunction with other specific obligations of Parties vis-à-vis indigenous and local communities in other provisions of the Protocol. In planning capacity-building activities, as far as these communities are concerned, Parties are to act with their effective participation, ${ }^{30}$ taking into consideration their customary laws, protocols and procedures ${ }^{31}$ and relevant international human rights norms. ${ }^{32}$

25 Nagoya Protocol Article 22(4)(a-d). See Greiber et al., Explanatory Guide, op. cit., 209.

26 Nagoya Protocol Article 22(1).

27 Nagoya Protocol Article 22(3). On the relevance of a human rights approach to gender discrimination in the context of the Nagoya Protocol, see Introduction to this commentary, section 4.3.

28 Nagoya Protocol Articles 6(2) and 7. See this commentary on Article 6, section 3, and on Article 7.

29 Nagoya Protocol Article 22(4)(j).

$30 \quad$ Undrip Articles 19 and 32(2); ILo Convention No. 169, Article 6(2); and fn. 54 in this commentary on Article 5.

$31 \quad$ Nagoya Protocol Article 12(1). See this commentary on Article 12, section 2.

32 See Introduction to this commentary, section 4. 
It should also be noted that most of the provisions in Article 22 referring to indigenous and local communities also aim to benefit other ABs stakeholders ${ }^{33}$ such as NGOs and the private sector, in cooperation efforts and in the selfassessment of capacity-building needs at the national level. Among the list of possible capacity-building measures, there is also explicit, although general, reference to increasing the capacity of relevant stakeholders in relation to ABS. ${ }^{34}$ This points to the underlying need for all ABs stakeholders to be well equipped to cooperate with one another in building effective and mutually beneficial ABs transactions.

The inputs of indigenous and local communities and other ABs stakeholders will also be sought at the international level, in the context of the proposed development of a strategic capacity-building framework under the Nagoya Protocol. ${ }^{35}$

Overall, the proposed approach to ABS capacity-building cooperation - that is, country-driven, mindful of financial solidarity obligations under the $\mathrm{CBD}$, and with the involvement of indigenous and local communities and other stakeholders - is expected to be reflected not only in the activities of the GEF and other sources of multilateral assistance for capacity-building purposes, but also that of national bodies that engage in unilateral and bilateral development assistance. This is particularly the case of those developed countries that are already providing or will provide development assistance with a view to facilitating implementation of the Protocol in developing countries.

Given the numerous legal complexities of the Protocol's subject-matter that will have to be addressed in building domestic ABs frameworks, and the challenges that may arise in particular ABs transactions, effective realization of capacity-building cooperation (or lack thereof) will be crucial for the Protocol's implementation by developing countries. As observed in other multilateral environmental agreements, capacity-related issues are strongly linked with compliance, particularly in the face of ever-expanding obligations under

33 Nagoya Protocol Article 22(1-2)

34 Nagoya Protocol Article 22(4)(i).

35 ICNP Recommendation 1/2, paragraph 1 and Annex, which refers to possible sequence of actions for the implementation of the strategic framework, including a possible roadmap of activities to assist countries in defining their priorities and corresponding timelines. 
international environmental law. ${ }^{36}$ It remains to be seen whether and how this link will play out, including in the deliberations of the future compliance mechanism of the Protocol..$^{37}$

Given the importance of capacity-building for ABs law-making and enforcement at the national level, support by developed countries to the development of ABS laws in developing countries will occur not only in the interest of the international community in the effective implementation of the Protocol, but likely also in developed countries' own interest (to ensure predictability and fairness for their users). It may be a challenge, in that context, to avoid exercising any undue influence or pressure on provider countries' exercise of their national sovereignty over their genetic resources and on indigenous and local communities. The delicate, and in many respects still open-ended, balance of international obligations enshrined in the Nagoya Protocol may thus create also risks that capacity-building initiatives may unduly favor the interests of user countries, if provider countries find themselves dependent on user countries' support. Another risk may arise from ready-made solutions offered through capacity-building activities that do not respond to the particular circumstances $^{38}$ of Parties, who will be under pressure to build national capacity to implement and ensure compliance with the Protocol. Such pressure may be heightened for provider countries, due to the link established by the Protocol between the domestic ABs framework of provider countries and user countries' international obligations on addressing compliance by their users. ${ }^{39}$

36 See Elisa Morgera et al., "Implementation Challenges and Compliance in MEA Negotiations," in Chasek and Wagner The Roads from Rio, op. cit., 222.

37 See this commentary on Article 30.

38 Examination of the history of (the failure of) conventional development assistance in this regard is beyond the scope of this commentary. For a succinct account of the debate, see David Ellerman, "Autonomy in Education and Development," Journal of International Cooperation in Education 7 (2004): 3, who notes 'a real danger that a development intervention, instead of acting as a catalyst or midwife to empower change in an autonomy-respecting manner, will only short-circuit people's learning activities and reinforce their feelings of impotence.' Ibid., 13.

See this commentary on Article 15, section 3.1. 